\title{
From Mises and Hayek to the planned and mixed economy. Planning criteria, basic income, guaranteed job.
}

\author{
Yaroslav Stefanov $^{1}$
}

\begin{abstract}
Arguments of Mises and Hayek, who opposed the planned economy (PE), are used in the paper as a starting point for establishing the objective area of effective application of the PE. The abstract model of PE, based on the definitions of Mises and Hayek, leads to the conclusion that for the effective use of PE, it must be a part of mixed economy and it must produce a limited amount of essential goods of irreducible demand. These goods must be distributed among all members of society free of charge, evenly, without competition. Examples of a mixed economy are given that meet this requirement. Calculations of the personal benefit in the transition to a mixed model of the economy have been carried out. The positive and negative qualities of the planned and market methods of organization are considered. Mixed economy model combines these qualities in optimal construction. An analytical framework has been introduced for the construction of product characterization curves. Such curves provide criteria for determining the efficiency of manufacturing of this product in a planned economy. The general economic prerequisites for the usability of the PE are clarified. The applicability and advantages of the PE for the organization of the universal basic income (UBI) system are demonstrated. The possibility of using PE to solve the problem of guaranteed employment is mentioned.
\end{abstract}

Keywords: planned economy, distribution, market economy, convergence, Mises, Hayek, universal basic income, guaranteed job

JEL classification: D30, P11, P20, P21, P22, P51, P52

1 Moscow State University; E-mail: yrsstf@gmail.com. 


\section{Introduction}

A theoretical discussion about the feasibility of a planned economy began in the 20s of the 20th century. (Lavoie 1985) Many abstract arguments have been proposed, but practice remains the main criterion. The arguments put forward by critics of the planned economy have mostly been justified in practice in USSR. The economic calculation problem described by Ludwig von Mises and Friedrich August von Hayek means the impossibility of rational allocation of resources due to the impossibility of objective prices in a planned economy. This problem was partly confirmed. Mises's position is that: "as soon as one gives up the conception of a freely established monetary price for goods of a higher order, rational production becomes completely impossible.” (Mises 1990).

The structure of the planned economy in the Soviet Union was not always the same. There is a huge difference in the functioning of the planned economy in different historical periods. But the problem of pricing has manifested itself to varying degrees at different times. It was not total "impossibility" to establish prices or "complete impossibility" of rational production, but rather problems with realistic objective price definition. Joseph Stalin mentions about "the confusion that still reigns in our pricing policy", he wrote: "Here is one of the many examples.... our planners made a proposal that could not fail to amaze the members of the Central Committee, since under this proposal the price per ton of grain was offered almost the same as the price of a ton of cotton, while the price per ton of grain was equal to the price of a ton of baked bread. To the comments of the Central Committee members that the price of a ton of baked bread should be higher than the price of a ton of grain due to the additional costs of grinding and baking, that cotton generally costs much more than grain, as evidenced by the world prices for cotton and grain, the authors of the proposal could not say anything intelligible." (Stalin 1952)

The economy of Stalin's period was not $100 \%$ planned. It was rather quasi-mixed model with nonstate sector. By the time this non-state sector was dismantled in the mid-1950s, it included 12667 cooperatives with 1844 thousand workers, 2 research institutes, 22 experimental laboratories, 100 design bureaus and produced 33444 types of goods. (Rizhiy, Pass 2012) A fully planned economy appeared only after the destruction of the non-state segment of the economy. Then the problems pointed out by Mises manifested themselves much more clearly. The main factor in establishing an objective price in a market economy is the ratio of supply and demand. As for soviet PE "the level of retail prices is determined by various factors and there is no direct dependence of demand and supply." (Kantor 1964) This independence from demand caused a shortage of many goods, which 
became a chronic problem in the late USSR. (Kornai 1990) On the other hand, the bias in the prices of some goods led to very strange phenomena. For example, the problem persisted for a long time, when villagers bought ready-made bread in stores to feed pigs. (Presidium of the Supreme Council of the RSFSR 1963) The price of bread was so low that such use of bread was beneficial to the peasants who wanted to sell the meat of these pigs in the market.

Mises and Hayek were mostly right in their criticism. But should their conclusions be considered the basis for a complete rejection of the idea of a planned economy? The point is that the reasoning of critics of PE is correct only within the established framework. This framework assumes, firstly, that the planned economy will be all-embracing, that is, that all the demand existing in a closed economic system will be satisfied by the products of the planned economy. And secondly, that the economy needs to use money. Such conditions are quite consistent with the practice of the planned economy in the late USSR, but are they really necessary?

As I'll show in this article, both of these conditions are not inevitable. In the theoretical model that I will build on the Mises-Hayek's definitions of PE, the rejection of these conditions turns out to be a natural continuation of their own logic. If to abandon the comprehensive character of the planned economy, and consider the model of a mixed economy, where part of the demand is covered by the planned economy segment, then the argument about the impossibility of an objective PE response to demand becomes meaningless in case when products of irreducible uniform demand are considered. If the demand for a certain amount of a certain type of product always exists, never decreases, and will be covered by the planned segment of the economy, then a response to fluctuations in this demand is unnecessary, because demand does not fluctuate.

Mises wrote about PE that "Calculation in terms of money will here be impossible." (Mises 1990). But using money in PE is not really necessary both for organizing production and for end distribution. The logic of a planned economy does not require the use of money, and, as will be shown below, the best solution for PE is to abandon money in favor of equal direct distribution. Mises considered monetary calculations to be the only possible way to determine the economic efficiency of resource allocation. But if the type and quantity of goods to be produced are strictly fixed, then the problem is no longer economic, but purely technical. In general, any production task, with consistent elaboration, turns from an economic to a technical one. It is possible to determine quite accurately when this moment of transition of the task from the economic field to the technical one comes. In market conditions, this moment comes when the task becomes an internal task within 
a firm. Within the firm, there is no market, no exchange, no money. The planned economy begins exactly where this transition of the task to the technical field takes place. In fact, the segment of the planned economy is one firm, one market subject. And from the point of view of the market, the transfer of a task for technical execution occurs exactly when it is already known what and in what quantity needs to be produced.

Supplementing the Mises-Hayek model with the discovered additional conditions, we obtain the definition of a planned economy, which immediately indicates the presence of a planned segment of the economy in most countries of the world.

This article deliberately uses the definitions of a planned economy given by its opponents Mises and Hayek. Based on these definitions, suitable model of PE is built. Examining this model reveals critical flaws in PE and shows how to work around them. In the course of consideration, identified shortcomings are overcome and conditions are found that allow effective use of the planned organization of the economy. Criteria for the correct choice of the field of application of the planned economy are also formulated. The benefits of using PE to implement an unconditional basic income (UBI) are then shown. The question of guaranteed employment will also be briefly considered in connection with the use of PE.

\section{Planned economy model, analysis, consequences}

Mises (1998) defined PE as "a system of social or governmental ownership of the means of production." In addition, Mises (1990) explained that "Under socialism, all means of production are the property of society. Only society can dispose of them and determines their use in production" (note that Mises uses "socialist" and "planned" systems synonymously). Mises also describes the most important characteristics of a planned economy: "The socialist system is a system without a market and market prices for the factors of production and without competition; it means the unrestricted centralization and unification of the conduct of all affairs in the hands of one authority" (Mises 1998).

No competition is present not only for the factors of production but also for consumer goods, since consumption is also planned: "All the wages, prices, and interest rates are fixed by the government; they are wages, prices, and interest rates in appearance only; in fact they are merely quantitative terms in the government's orders determining each citizen's job, income, consumption, and standard 
of living" (Mises 1998). Regarding governance, "All plants, shops, and farms are formally nationalized...; they are departments of the government operated by civil servants" (Mises 1998).

Based on the above characteristics, consider a theoretical model of an isolated economic system (island) where 100 people live. These are people who produce some kind of product. Following Mises (1998), "We may for the sake of argument at first disregard the dilemmas involved in the choice of consumers' goods to be produced. We may assume that this problem is settled." This model follows Mises' assumption. Moreover, for simplicity, I will assume that only one type of goods is produced in the amount of $\mathrm{N}$ units per month.

Assume that one out of 100 people was chosen by all the other 99 residents in a direct vote to manage their economic activities. I call this person's role "planner" (PP). PP then proceeds according to the norms of a planned economy

Production. In this fantastic case, only one type of goods is produced. For this production, the inhabitants of the island have the raw materials and tools. How people will manufacture their product is a technical issue. Mises wrote: "Technology... is at a loss to tell man which procedures he should choose out of the infinite variety of imaginable and possible modes of production.”. But in the case that it is known what to produce, there is no need to choose from "infinite variety", because at the existing technological level there is usually only one-two technical solution. The question of how the PE knows what to produce and in what quantity will be discussed later. It is only important to note here that knowing the purpose of production, one can also choose the appropriate technology for production. And in the technological field there are clear parameters of efficiency: to produce the required amount of products of acceptable quality with lower material and energy use. This criterion is enough to choose one of several available technologies. In the case when it is necessary to plan not one production, but a production chain, then it is necessary to consider a joint technical problem in which the output of one production is the input of another. Searching for a solution to such a problem from the technical view allows to find the best solution.

Distribution. The task of PP is to organize the distribution of $\mathrm{N}$ units of production among 100 people as fairly as possible. In this article, "fairness" means the approval of a decision made by the overwhelming majority (nearly $100 \%$ ) of members of society.

Suppose that PP decides to organize distribution in the way that is usual today, through payments of 
money to all residents. With this money, residents will buy products. PP faces several questions:

-How much money will be generated (money is completely in the power of PP)?

-What will be the monthly salary to residents?

-What is the price for products?

The task of PP is to distribute products fairly so that there are practically no dissatisfied people. What will PP do? To begin, the amount of money created is irrelevant because prices and wages are also set by PP. Let PP create 100 coins to make it easier to distribute this money among residents. Everyone receives one coin a month. To ensure that all products are equally distributed, PP sets the price per unit of production to $100 / \mathrm{N}$, so that for each unit of production there is an equal amount of money. For example, if $\mathrm{N}=100$, then the price will be one coin per item.

Does PP have other options for setting salaries and prices? Note that PP has no other options that do not create problems for him and everyone around him. For example, if PP makes the total price more than the total salary, then there will be unallocated products for which the residents did not have enough funds. If PP distributes more money than the total price of the product, then someone will have opportunity to buy more than others and someone else will not have enough products. Both variants are bad for the system. There is one more question: will everyone be happy with an equal distribution? We will look at this issue later.

Next, a detached view of PP's actions at the end of the month is considered. First, PP gives everyone a salary then exchanges coins for products with all residents. If PP begins to perform all these operations not with all residents but with each individual person in turn, then it would appear as the following:

- Give a coin (provide a salary)

- Take a coin (get paid for a product)

- Give the product

It seems that these operations can be simplified. Does PP need to give and take back a coin? Apparently, this makes no sense at all. It is clearly seen here that in a planned economy, which is modeled according to the Mises scheme, the presence of money is not necessary. In what follows, it will be shown that this is true not only for this simple case, but also in the real economy. 
To complicate the task, consider the case of several types of products that differ in the consumption of raw materials, energy, labor, and time for there production. Moreover, due to high raw material consumption and limited technical capabilities, the production of some goods is possible only in small quantities. Perhaps this situation will require the use of money?

If the money is used for distribution, then the task of PP is to set fair prices. However, it now becomes much more difficult to solve the problem of fair distribution with the help of money. For example, it is possible to arithmetically calculate certain coefficients of the consumption of time, energy, raw materials, and more during production, setting prices according to these costs. But then the question is, does the distribution that arises at these prices meet the needs of the residents? Even if it is possible at some point to establish fair prices for the equilibrium distribution, then over time, needs can change rapidly, and after a short time, the previously set prices will turn out to be nonequilibrium.

In the case of a market distribution, prices change in response to changes in demand. Since distribution is competitive, an increase in demand means an increase in competition for a given product. Increased demand is expressed in a willingness to pay more for the same product. In this case, the price is increased by the sellers, thus, the number of consumers able to pay the new price decreases, and the balance of supply and demand is restored. Market distribution mechanisms provide feedback between consumers, sellers, and producers. The market provides the consumer with a form of leverage with which to both increase and decrease production. Due to general rivalry, feedback mechanisms are objective, that is, they depend not on the wishes of one person or a group of people but on the ratio of their desires and financial capabilities.

The situation is completely different with a planned economy. As the distribution decision is made centrally, a general pricing principle is required corresponding not only to technical capabilities but also to actual needs. PE needs a general pricing principle that matches both the personal assessments of people and the objective capabilities of the economy. However, it is almost impossible to propose a universal principle approved by society overall. As Mises (1962) writes, "It would be fundamentally impossible to base distribution on the imputation of value because it is an essential feature of socialistic methods of production that the shares of the different factors of production in the result cannot be ascertained; and any arithmetical test of the relations between effort and result is impossible." 
In addition, the needs of different people do not coincide. One person needs something more and another less. Within the framework of the PE, as soon as someone tries to distribute something unevenly and noncompetitive, fundamental questions arise: "What criterion should be used to give one person more and another person less?". Is there a way that the overwhelming majority considers fair? It seems that such a method cannot be proposed. The fact is that each person, seeing his own advantages and other people's shortcomings, can consider himself deprived. For example, someone may think that they are performing better than others, or may actually perform better, but it is not always possible to objectively measure a person's contribution. Therefore, it would be impossible to find an objective, universal mechanism for unequal distribution.

If the demand situation is stable, meaning restricted uniform demand does not change, and the technical parameters of production remain unchanged, then it is much easier to solve the distribution problem above without using money. In this case, there is no pricing problem at all. It only remains to distribute products evenly across residents over time. If some production per month is not enough for everyone, then the PP will be able to distribute the available quantity in the current month, and those residents who have not received product this month will receive it in the next. Uniform distribution solves the problem of PE in the general case. It should be emphasized that the preferable condition for a planned economy is a fixed demand. A known-constant, limited demand allows the use of a constant production capacity and does not require a response to fluctuations in demand. This is a crucial point that can aid in subsequently determining conditions for the effective application of the PE.

At the beginning of our consideration, we followed Mises in assuming that the problem of choosing the goods to be produced had already been solved in advance. In reality, this problem always exists and plays a key role. In fact, when planning production, one must first answer the two questions of what and how much to produce. Again, it is necessary to return to the dependence of production on demand. How should a planned economy answer these questions if the decision is not made on the basis of demand? As Hayek (2005) writes,

All the details of the changes constantly affecting the conditions of demand and supply of the different commodities can never be fully known, or quickly enough be collected and disseminated, by anyone centre, what is required is some apparatus of registration which automatically records all the relevant effects of individual actions, and whose indications are 
at the same time the resultant of, and the guide for, all the individual decisions. This is precisely what the price system does under competition, and which no other system even promises to accomplish.

Many planning theorists and practitioners have thought of implementing the "price system" mentioned by Hayek (2005) in a non-market manner. The solution seemed to be building a computer system to quickly track changes in the economic situation and make the necessary adjustments to the existing production plans and prices (Berg et al 1959). As Glushkov (1975) suggested, "To plan and manage the actual levels of retail prices, it is necessary to have a system of continuous monitoring of current and future demand." Of course, computer systems can improve the quality of planning, but the question remains whether these systems would help solve the problem of feedback from consumer to manufacturer.

Suppose a computer system can quickly track fluctuations in demand. Whether the system is a market or planned economy, the starting point for information about demand is the consumers themselves, by attempting to satisfy their needs. Moreover, in a market environment, consumers vote with limited available money. In contrast, a planned environment can only rely on direct requests from consumers. The most important circumstance here is the absence of objective constraints when persons declares their needs. Needs are basically subjective and may appear significant to people. Without an objective mechanism to limit needs, if we rely on requests from people, we would simply transfer human fantasies about a sweet and rich life to the automatic planning system. The PE system itself does not have built-in feedback mechanisms that ensure objective regulation of production based on the correlation of society's needs, and no automatic system can change this fact. Mises and Hayek were correct about that limitation.

This point leads to the fundamental question of whether a planned economy should reacts to any fluctuations in demand whatsoever. We noted above that the PE works well in a stable demand environment, which means that planning must be applied precisely in such conditions. Therefore, PE should be used in the production of such goods where demand is stable and will not decrease in the foreseeable future. The quantity of products must be such that all of them are consumed if evenly distributed. For an efficient operation of the PE, it is necessary to produce a constant amount of products. If the quantity needs to be changed, then such changes must first be predictable, and second, slow enough so that a change in production does not require drastic changes in the plan. This issue is addressed in more detail below. For now, let's continue to look at the problem of 
money in PE.

The examples of the speculative models discussed above demonstrated that a planned economy can easily do without money if the distribution is properly organized. The question is whether everything would be different in a transition to a real economy. Let's identify the factor that permits to give up money. This factor is that the creation of money and the establishment of prices and wages is centralized, planned by one economic subject within the subordinate area. In the model above, if PP is understood not as a person but as a planning organization, then an accurate picture of a planned economy is obtained. Note that this model exactly corresponds to the characteristic Mises provided regarding centralized control in a PE. Moreover, this characteristic always works in a planned economy, which means that the possibility of surrendering money in a planned economy is also always present and is a key circumstance.

The reason for the possibility of giving up money in a planned economy in a broader sense is that distribution in such a system is noncompetitive and takes place within the framework of one economic subject. Money in a market economy is an instrument of competition between different economic subjects, where the wealthier gain access to more goods while others must first raise money to obtain the desired level of wealth. In a planned economy, as Mises and Hayek rightly noted, distribution occurs without competition. Even if money is introduced into the planned domain, its role would be fundamentally different from that of the market economy. In the PE, money plays the role of a certificate for obtaining the person's share of the manufactured products because the manufactured products, like the means of production, belong to the entire society. Therefore, giving up money in PE is easy, especially if a list of whom and what to distribute is prepared in advance. In this case, for the preliminary compilation of the corresponding list, the computer system of pre-orders mentioned above would be useful, allowing consumers to choose the desired products in advance. As mentioned, the planned domain should produce things of constant demand in limited quantities. This means that the plan pre-sets the maximum amount of each product available to the consumer. In the case of computer orders, the consumer would be able to choose the amount of products needed, but not more than the established limit. The consumer might probably prefer to choose one of two alternative products, but even in this case, the plan determines in advance the maximum amount of product available to everyone.

Thus, the following rules for the best application of the PE emerge: 
- In the planned economic domain, products are produced focusing on irreducible demand.

- The number of products must be guaranteed to be consumed by the society. This amount is either constant or changes slowly and predictably.

- Products are distributed among all members of society free of charge, evenly, without competition.

Note that under equal distribution, all people would not necessarily receive exactly the same amount of product. Physiologically determined, objective criteria permit singling out certain groups of people who need more or less of a certain product, for example, the groups "children," "workers," or "retirees." If we distribute "fairly," then the absolute amount of the product needed for children would be less than what an adult needs. Such a standardization is completely objective and therefore accepted by all members of society, that is, it is fair. In what follows, "equal" distribution means "equal considering physiological normalization."

\section{Mixed economic system}

Proceeding with the imaginary model, suppose that the island population, after a vote, decided to unite with a larger neighboring island (400 people) with a market economy. Simultaneously, it was agreed that in the united economic system, the small island would supply all residents of the united country with certain products. In return, the inhabitants of the smaller island would have access to market goods, that is, they receive money from the big island.

The terms of cooperation are that the products of the small island with the PE are to be distributed free of charge and evenly among all residents of the united country. Likewise, the money received from the market economy on the big island would also be "equally" (in the sense of the mean value) shared with small island. Thus, in the case of the model shown in the picture (i3), the "consolidation tax" is $20 \%$ in the market domain and $80 \%$ in the planned domain.

Note that the union conditions presented in example (i3) are "bad" in a certain sense. That is, the market domain has not only workers who receive wages but also capitalists who receive, in addition, profits. For an honest association, this circumstance must also be considered. For this analysis, this condition is unimportant as the focus is on the mechanisms of unification and cooperation of the two systems. 


\section{Before combining}

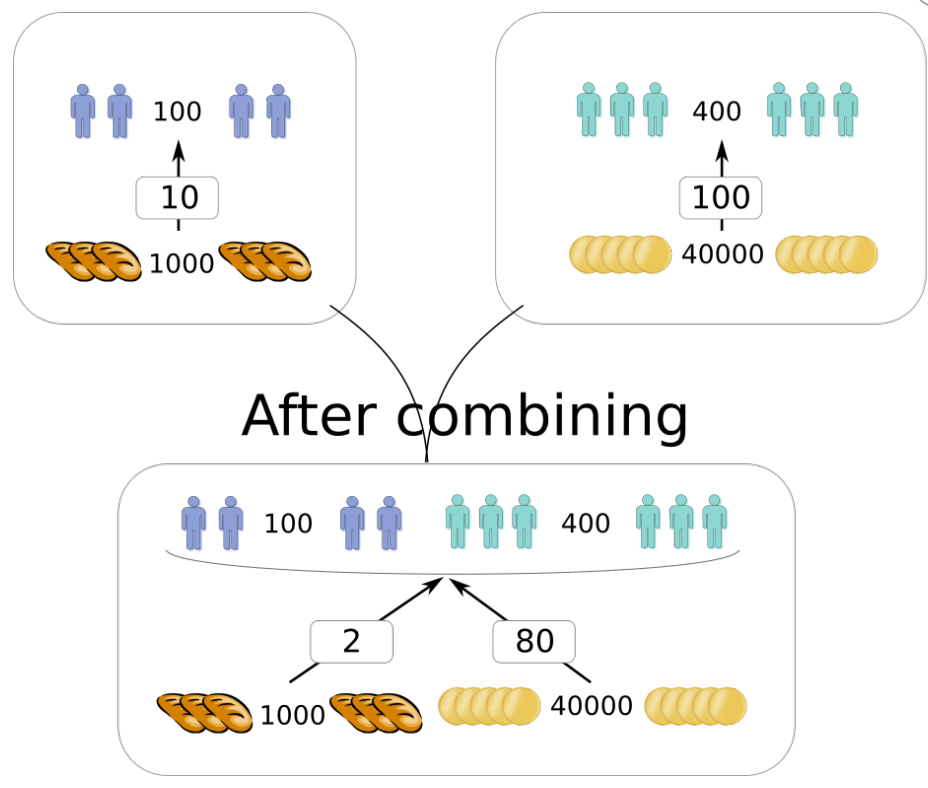

In such an association, each party receives benefits. The small island (planned domain) get access to a variety of goods from the large island (market domain). The market domain gets access to the products they need for free. The question arises whether it would be unprofitable for "market domain people" to share money with "planned domain people." Perhaps the amount of money that the market side person loses due to the merger would be more than their costs for the same product in the pure market economy. This question is worth examining in more detail.

To find out which option would be more profitable, costs should be calculated for both cases. Let there be a market economy producing P. One can divide this economy into two parts. The first part includes everyone who works in the production of $\mathrm{P}$ and those who are financially dependent on these people. The number of people in the first group is $\mathrm{Np}$, who receive a market salary Zp. The rest comprise the second group in the amount of $\mathrm{Nm}$ people who receive a total salary of $\mathrm{Zm}$. The scenario is that, at first, both parts are in a single market economy. Next, the first part is reorganized into the PE domain. One can calculate the cost of the product $\mathrm{P}$ for people in the second part before and after this reorganization to see which is more beneficial for them.

We believe that in this market economy there is competition in the labor market, which leads to a homogeneous distribution of wages, that is, approximately the same wages are paid for the same job. This wage competition leads to average salaries in different parts of the economy being approximately equal if the nature of the work is approximately the same. In a fairly large economic sector, there are various types of work. We consider selected areas of the economy large enough to 
have a variety of jobs. In that case, the average salary in the two parts would be the same:

$$
\frac{Z_{p}}{N_{p}}=\frac{Z_{m}}{N_{m}}
$$

In addition, as product $\mathrm{P}$ is regarded as suitable for the planned economy, consumption of the product is considered uniform and irreducible, that is, it is consumed equally by all members of society. Thus, in a purely market economy, the costs of the product $\mathrm{P}$ attributable to each person would be:

$\frac{Z_{p}+Y+X}{N_{p}+N_{m}}$

The numerator contains the total market value of sales of the product P. Here, $\mathrm{Y}$ is the production component of the price (cost of raw materials, depreciation of equipment, etc.), and $\mathrm{X}$ is the market component. It includes all those other costs of the market economy for which end consumers pay, namely, payment for competition (marketing, advertising, etc.) and the profit of enterprise owners.

Now let's move on to the next step, when the first part will be reorganized into a PE domain. Estimates of the costs of $\mathrm{P}$ for the second part members $\mathrm{Nm}$ are now needed if the first part becomes planned. In this case, a portion of the salary of the second part members Nm would be given to the first part, while the average salary should remain equal. To calculate the average salary, production costs $\mathrm{Y}$ must first be subtracted from the total salary $\mathrm{Zm}$ (we consider the worst-case scenario, when all production costs are market costs), then the remainder is divided by the sum of all people:

$$
\frac{Z_{m}-Y}{N_{p}+N_{m}}
$$

The salary in the second part before the separation of the planned domain was $\frac{Z_{m}}{N_{m}}$. After the separation, the salary decreases by

$$
\frac{Z_{m}}{N_{m}}-\frac{Z_{m}-Y}{N_{p}+N_{m}}
$$

The result represents the cash expenditure of the worker in the second part $\mathrm{Nm}$ on the product $\mathrm{P}$ in the case of a separation of the planned economy part. Next, it is necessary to see in which cases market costs would be higher than planned, that is, when the allocation of the planned segment 
would be beneficial for those who work in the market domain. This condition:

$\frac{Z_{p}+Y+X}{N_{p}+N_{m}}>\frac{Z_{m}}{N_{m}}-\frac{Z_{m}-Y}{N_{p}+N_{m}}$

can be converted to:

$\frac{Z_{p}+Y+X}{N_{p}}>\frac{Z_{m}}{N_{m}}+\frac{Y}{N_{p}}$

or

$\frac{Z_{p}}{N_{p}}+\frac{Y}{N_{p}}+\frac{X}{N_{p}}>\frac{Z_{m}}{N_{m}}+\frac{Y}{N_{p}}$

Considering (1), I obtain

$\frac{X}{N_{p}}>0$

This inequality is always true in a market economy because the main goal is to make a profit. If the market economy is functioning, the market cost $\mathrm{X}$, which includes the profit, will always be greater than zero. Therefore, under the conditions determined above, cash expenditures of workers to obtain the product $\mathrm{P}$ would be less in the case of a planned economy where both systems are combined.

It is now necessary to assess how realistic it is to mix a planned and a market economy. Perhaps there are fundamental reasons that do not allow such a "symbiosis." Both Mises and Hayek unanimously agreed that unification is impossible. Mises unequivocally stated that "they can never be confounded with one another; they cannot be mixed or combined; no gradual transition leads from one of them to the other; their obversion is contradictory" (Mises 1998).

"Both competition and central direction become poor and inefficient tools if they are incomplete; they are alternative principles used to solve the same problem, and a mixture of the two means that neither will really work and that the result will be worse than if either system had been consistently relied upon" (Hayek 2005).

The following properties were discovered by logically evolving the definitions of PE given by Mises:

- PE is public and belongs to the state (the means of production are public or state property)

- Employees of the PE are in the public service and receive funds from the state 
- PE is managed by government officials who prepare production and distribution plans

One more item was added, which logically follows from the original Mises's model:

- In the PE, products of irreducible demand are created. They are produced in a limited required quantity and distributed among all members of society free of charge, evenly, without competition.

Rather than analyzing the theoretical possibility of combining a planned and a market economy, we can observe reality. For instance, consider the modern realm of school education. In the state domain, government officials provide citizens with a free education service for children. The administrators operate according to a predetermined plan based on a fixed demand, objectively determined by the number of school-aged children. This process exactly corresponds to the above definition of PE. One can see that this school-educational planned domain is embedded in the market economies of most countries in the world. As a rule, the entire field of educational services is not limited to government schools. Usually, in addition to the state, there is also the private sector, where one can obtain education on a market basis. That is, even in the same educational area, the plan and the market get along easily. School education is not the only example of a planned approach. In many countries, free health care is similarly structured. Moreover, the process of the emergence of new planned domains is not limited to these sectors.

It appears that the combination of plan and market is not only possible but exists right in front of us. In such conditions, it is doubtful to discuss the impossibility of their combination. It is now possible to use the approach proposed in the beginning of the article suggesting that the plan and the market are just tools. Their use in combination or separately should depend on the objective correspondence of the pros and cons of each approach to the economic problem being solved.

\section{The principle of separating the plan and the market}

The following represents the most significant advantages and disadvantages of each of the systems.

\section{Planned economy.}

Pros: A planned economy is better suited for the efficient production of a large number of products of a fixed range and quality: 
(a). Quantity: Due to the enlargement and automation of production, the larger the production, the lower the cost of materials and labor per unit of output. The more automation, the less labor per unit of output. The state has enough capabilities to combine science and production and focus on automation, even if this requires a lot of resources and time in the first stage.

(b).Efficiency: Planned economies generate efficiencies due to centralized planning and reduction of overhead costs when interfacing related industries.

(c). Quality: As planned economy is not restricted by the boundaries of making a profit, it is possible to make products of exceptional quality, which is unacceptable (i.e., unprofitable, not bringing profit quickly enough) in the market part of the economy.

(d). As distribution occurs within the framework of one economic subject, consumers receive products through the internal distribution system more evenly and fairly than in the case of the market.

Cons:

(a). In the planned economy, enterprises are included in the general economic plan. Making changes to the production plan of one enterprise requires changing the plans of all other enterprises on which the enterprise depends. As a result, planned production is inflexible. It would seem that the sluggishness of planned production can theoretically be significantly reduced by:

1. More modern production technologies, so that it is possible quickly switch from the release of one product to the release of another, and

2. A prompt introduction of changes to planned calculations.

The question is for what such a flexibility permits a rapid response? Changes in demand? But a fundamental problem of the PE - the absence of objective mechanisms for responding to demand, which has been discussed above. In the PE, the effort to increase flexibility may simply be useless. Thus, another negative property is fixed: 
(b).For a planned economy, no feedback levers supply the producer with objective information about consumer demand. Producers and consumers, unlike the market, are not rivals. No imaginary rope is held between them, which they drag in different directions, creating a feedback mechanism.

Next, the market economy is considered.

Pros: Marketed establishments are better suited to produce variable assortment and quantity of products with a wide range of varied qualities with less overall efficiency.

(a). Quantity: Market enterprises can produce both a lot and a little, depending on the demand. If enterprises cannot compete in the market, they simply close down or rebuild production to produce other goods. It is also easy to open new enterprises if a new niche of demand has appeared on the market.

(b). Quality: Market enterprises strive to occupy all possible niches of demand, so the quality can be either very low or very high, or anything in between.

(c). In market conditions, the price can be (but is not always) an objective indicator of the ratio of supply and demand. If the market price is the result of the struggle of different subjects, an equilibrium point of oppositely directed forces exists. In that case, the market price is objective.

(d). The market mechanism of the struggle for an objective price works as a feedback lever from consumer to producer. Through the market, the consumer gives a signal to the manufacturer to either increase or slow down production.

Cons:

(a). Low efficiency on the scale of the economy as a whole. A market enterprise competes with other manufacturers, and this competition requires a lot of additional costs. The costs of marketing, advertising, product appearance, etc. - all these costs are borne by each company individually and then paid by consumers. In addition, competition can cause the losing 
product to end up in a landfill. Market rivalry requires a significant additional expenditure of all resources from society.

(b). The goal of a market enterprise is profit, which is also, in a general economic sense, an additional pointless expenditure of funds. In addition, making a profit generates negative political consequences, but this topic is beyond the scope of this article, so it is not considered in detail.

(c). Before a consumer buys a product on the market, they must obtain enough money. Moreover, even with hard work, there is no guarantee that each consumer will earn enough money for the product they need. The distribution is uneven.

The conclusion is that, due to its natural characteristics, the planned economy does not have the tools for a realistic assessment of the amount of output required by society. At the same time, however, the production itself is more efficient. Therefore, in the planned economy domain, it is reasonable to produce such goods that the consumer objectively needs in quantities that do not exceed the minimum physiologically or socially determined demand. All other products will be more efficiently produced in the market economy domain.

After formulating the principle of separating plan and market, consider Hayek (2005): "The planning authority cannot... tie itself down in advance to general and formal rules which prevent arbitrariness." From the above principle of separation, it is obvious that the planning authority can operate in a stable, strictly established coordinate system, set not only by "general and formal rules," but in a much more reliable way — through human physiology.

Moreover, the given principle helps answer the questions asked by Mises: "In which branches should production be increased or restricted, in which branches should the objective of production be altered, what new branches should be inaugurated?" (Mises 1998). As PE focuses on physiological or socially conditioned objectives of irreducible demand, then the question of determining the quantity produced is purely technical because the answer depends only on the size and age composition of the population. The question of choosing goods produced in the planned economy, however, requires more careful consideration. In any type of economy, both over- and underproduction are a significant problem. For the planned economy, it is necessary to determine what types of products and in what quantity will be guaranteed to be in irreducible demand. These 
issues are considered next.

\section{Some general qualitative characteristics}

Before consideration of the question posed, it is necessary to define some numerical parameters. The level of living in society depends on the amount of products that will be received by the consumer. To achieve a certain level of living, the required amount of different goods will vary. The level of living will be measured by the number L. For a certain product $\mathrm{P}$, it is possible to graphically depict the dependence of the amount of production $\mathrm{N}$ required by the whole society on the level of living L:

$\mathrm{Np}=\mathrm{F}(\mathrm{L})$

This function answers the question "How much product $\mathrm{P}$ is needed to achieve the L level of living?" In what follows, instead of Np, I will simply write $\mathrm{N}$, keeping in mind that the term refers to one specific product $\mathrm{P}$, unless otherwise stated. Usually, in economic theories, the reverse approach is used, where a certain numerical characteristic is considered depending on the amount of available product. With this approach, I would use the function

$\mathrm{L}=\mathrm{G}(\mathrm{N})$

However, in the current consideration, the approach $\mathrm{N}=\mathrm{F}(\mathrm{L})$ appears to be more convenient. Note that the level of living $\mathrm{L}$ can be associated with the general utility $\mathrm{U}$ of all goods consumed in society. To do this, it is first necessary to note that according to one of the central ideas of utility theory (UT), all main needs are limited. According to Jevons: "All our appetites are capable of satisfaction or satiety sooner or later, both these words meaning, etymologically, that we have had enough, so that more is of no use to us." (Jevons 1871). Therefore, with an increase in the available amount of a product, at some point a saturation level will be reached, and no more of the product will be consumed. The maximum possible level of utility Umax will have been reached. Based on this, I can assume that an increase in the level of living means an approach to the maximum possible level of received utility. The closer society comes to this maximum boundary, the higher is the level of living. As a first approximation, for a qualitative consideration, this dependence of $\mathrm{L}=\mathrm{L}(\mathrm{U})$ can be represented as follows: 


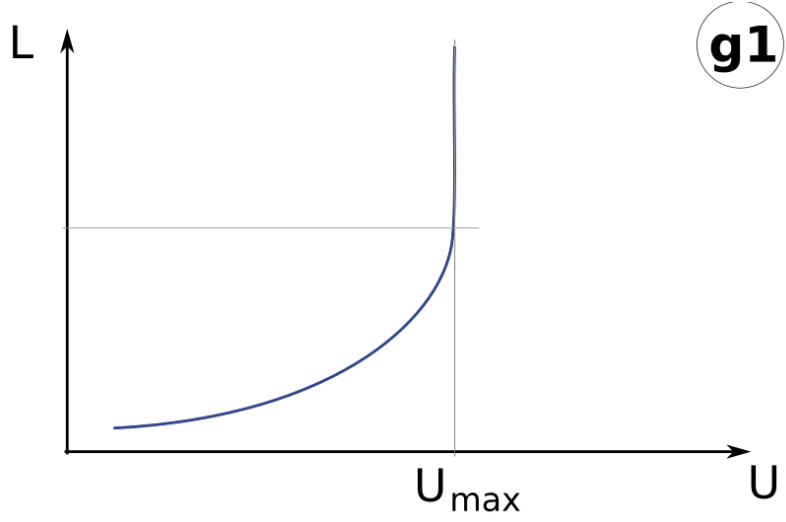

Here, the achievement of the maximum level by the utility leads to an infinite value of the level of living, which can be understood in such a way that a further increase in utility no longer affects a further increase in the level of living. Based on (g1) and the provisions of the UT, conclusions can be draw about the behavior of the function (6), which should be considered later. The utility function $\mathrm{U}$ for a specific product $\mathrm{P}$ in the area $[0, \mathrm{Umax}]$ is an increasing function of the amount $\mathrm{N}$ of the product $\mathrm{P}$. Thus, in this area, the maximum value of utility corresponds to the maximum amount of production, Nmax. Moreover, when this amount is reached, the value of $\mathrm{L}$ in formula (7) goes to infinity. For the inverse function (6), I obtain that there is a certain maximum value Nmax at which, upon reaching the point Lmax, the function $\mathrm{L}$ ceases to change on the ray $[\mathrm{Lmax}, \infty)(\mathrm{see}$ i4).

The behavior of function (6) is quite understandable, meaning that an increase in the consumption of the product $\mathrm{P}$ to a certain level of living Lmax will satisfy the needs in society, and a further increase in the number $\mathrm{N}$ is no longer required. Before giving an example of a graph of function (6), the scale of the value $\mathrm{L}$ is set. The following living levels can be roughly distinguished (Buletova et al. 2014):

(1). Extreme poverty (EP) (minimum consumption of goods and services at the level of human biological survival),

(2). Poverty (PW) (consumption of goods and services at the level of the ability to maintain a person's working capacity),

(3). Normal level (NM) (consumption of goods and services according to scientifically grounded norms, which are sufficient for the full restoration of the physical and intellectual forces of a person),

(4). Prosperity (PR) (use of benefits and services that ensure the comprehensive 
development of a person).

Within the framework of this article, the graph of function (6) for product $\mathrm{P}$ will be called the "characteristic curve" of product P. An example of a graph of the characteristic curve with marked points $1-4$ follows.

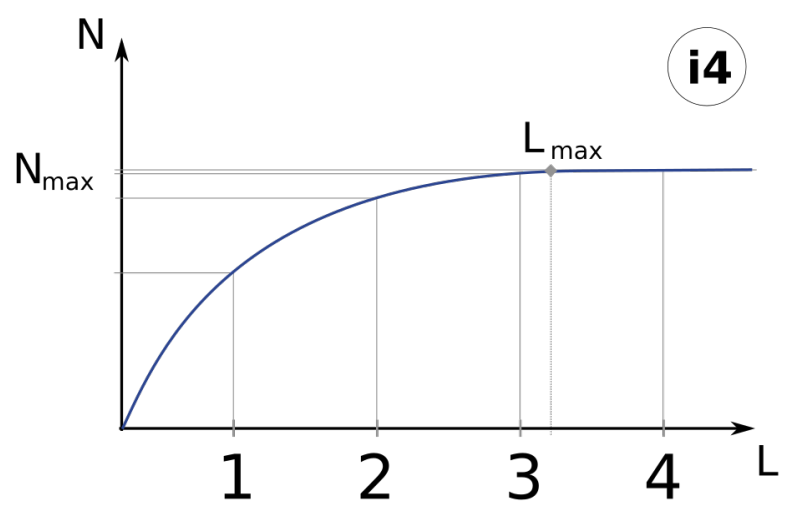

On chart (i4), levels 1-4 are marked on the L-axis . Each selected point 1-4 corresponds to a certain amount of production P, which will be denoted as N1-N4. On the initial segment of the given graph, approximately up to point 1 , the demand for the corresponding quantity of the product is physiologically determined. Below point 1 is the area of survival, so variations in demand are impossible. The further the L-coordinate moves away from the origin, the less certain the demand becomes, and the more the amount of $\mathrm{N}$ depends on subjective or random circumstances. If at the beginning of the curve, the quantity $\mathrm{N}$ is determined by physiology and does not allow variations in demand, then further variations in demand can be significant.

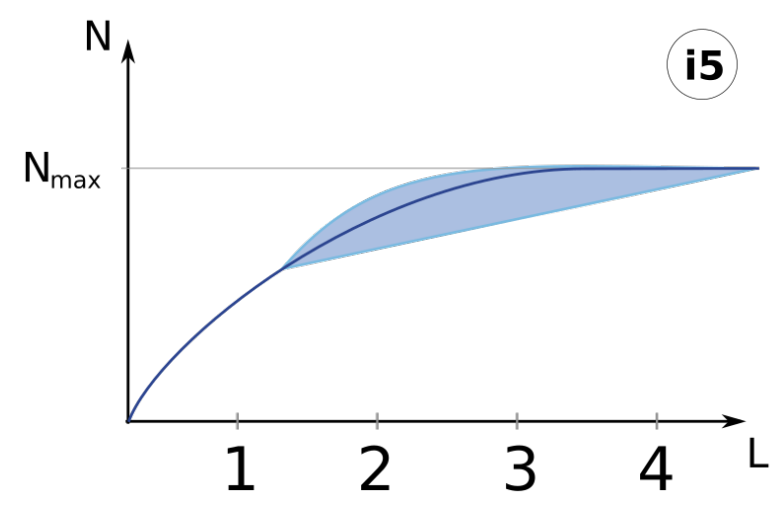

On the graph (i5), an expanding band shows possible fluctuations in demand for different living levels. From the point of view of the applicability of the planned economy, when demand stability is required, the amount of output $\mathrm{P}$ should correspond to the area of no fluctuations in demand, as made clear on the graph.

Characteristic curves for the two examples are now constructed. Consider the consumption of bread products (i6). 


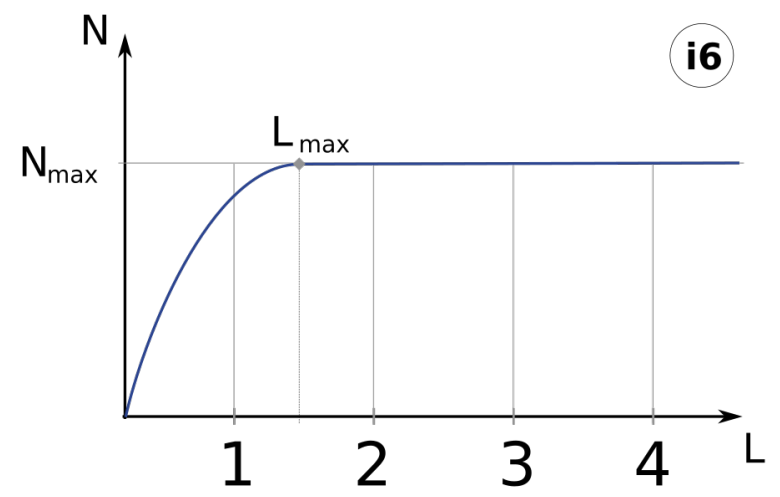

In this case, the Nmax limit will be reached rather quickly, after which the consumption of bread products will not increase. For example, in the case of Russia, Nmax for bread is about $120 \mathrm{~kg} / \mathrm{year}$ (EMISS 2021):

Потребление основных продуктов питания ( в расчете на душу населения) (значение показателя за год)
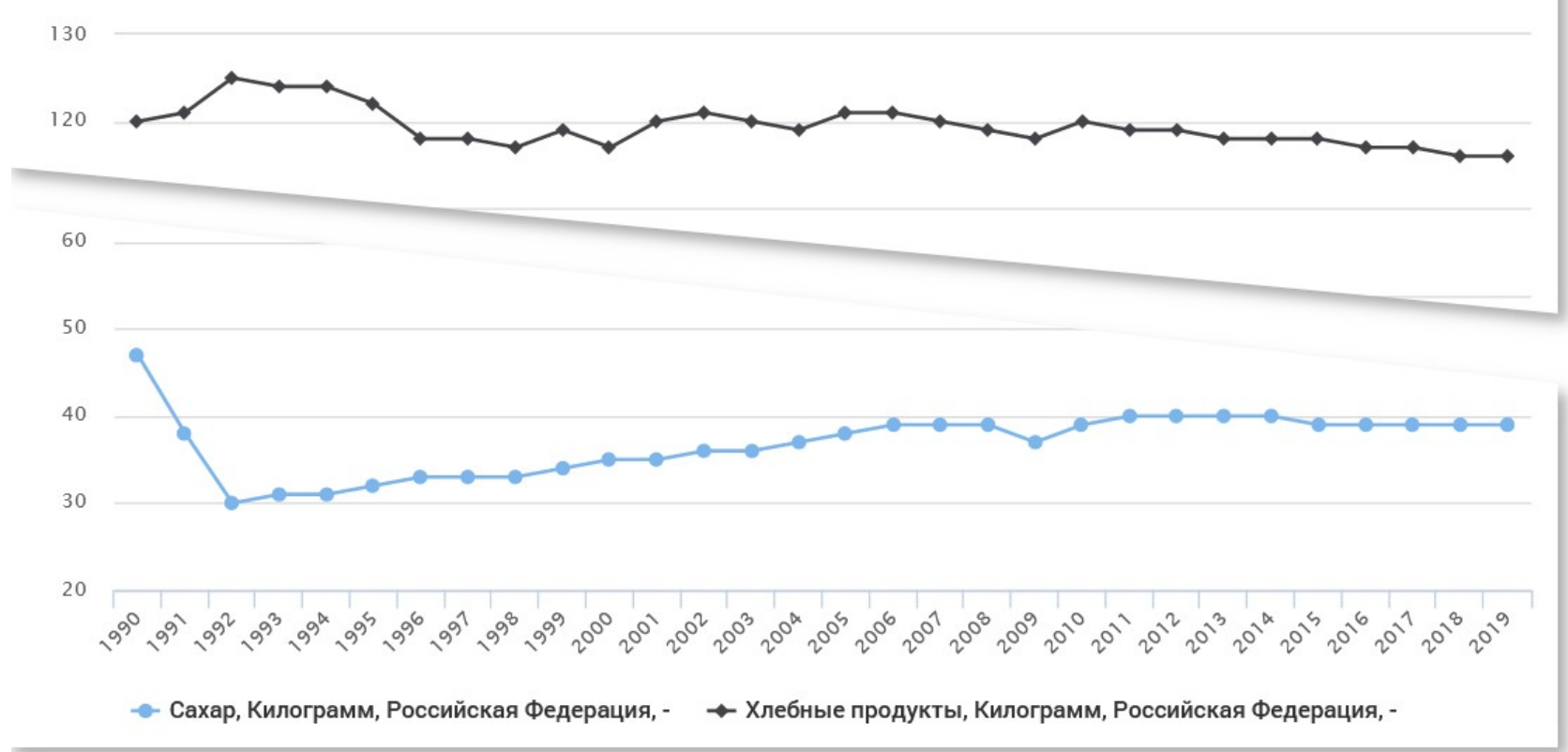

Fluctuations in the consumption of bread (black line) for the indicated period of 30 years are about $8 \%$. For comparison, a graph of sugar consumption is shown (blue line), for which fluctuations in consumption in the hungry 90 s were more than $40 \%$. Thus, even with a low level of living on the verge of survival, the demand for bread did not decrease and the consumption of bread products remained at approximately the same level. A curve for the comparison for gold jewelry with precious diamonds can now be derived: 


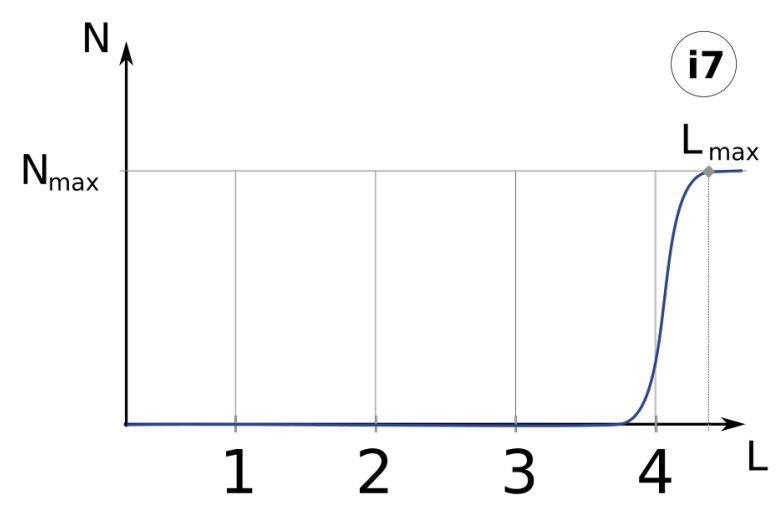

The demand for these kind of goods will rise only with a sufficiently high level of living. Until then, such luxury goods will not be in demand essentially.

Characteristic curves can be constructed for any kind of consumer products based on both theoretical studies (for example, for physiologically necessary products) and on the basis of statistical data.

\section{Product selection criterion for the planned economy domain.}

Return to the questions of what rules help identify the most suitable types of products for the planned domain and how to establish the required amount of these products. To answer these questions, the principles of the planned economy formulated earlier are applied to the consideration of the characteristic curves from the previous section.

As a first approximation, I single out a class of such goods for which the risks of encountering problems caused by the peculiarities of the PE are minimal (first stage). Then, I reduce the requirements and identify products with small risk (second stage). Since planned production requires goods of irreducible demand, suitable classes of products for the first stage of planned production will be those that have a characteristic curve with nonzero values of $\mathrm{N}$ on the interval $\mathrm{L} \in[0,1]$. Thus, a sufficient condition for the production of $\mathrm{P}$ in the PE domain is:

$$
\begin{aligned}
\mathrm{N}(\mathrm{L}) & >0 \text { for } \mathrm{L} \in[0,1] \\
& -\quad \text { product selection condition }
\end{aligned}
$$

The following condition answers the second question of how much to produce: 


$$
\begin{aligned}
\text { Nplan } & =\mathrm{N} 1=\mathrm{N}(1) . \\
& -\quad \text { planned production level }
\end{aligned}
$$

Conditions (9) and (10) distinguish a group of products of minimum risk. In fact, these are all life support products in the minimum amount necessary to support life (some food, shelter, heat, energy, etc.). Such products are always needed and are not subject to fluctuations in demand. Since the quantity produced is the minimum required, the fairest distribution is equal distribution. Provided to citizens free of charge, such products ensure a reliable basis for the life of every person.

For the second stage of the planned economy, weaker conditions can be established:

$$
\begin{aligned}
& \mathrm{N}(\mathrm{L})>0 \text { for } \mathrm{L} \in[0,2] \\
& \text { Nplan }=\mathrm{N} 2=\mathrm{N}(2)
\end{aligned}
$$

These conditions make it possible not only to cover the basic minimum needs but also to provide citizens with a guarantee of physiologically sufficient provision of their most important needs.

In theory, a similar approach could also be used to meet the basic needs of businesses. I do not discuss enterprises of the PE domain, which are not independent economic subjects. This refers to market enterprises. Probably an effective solution may be to freely provide such enterprises with a limited amount of necessary equipment on terms that are beneficial to both these enterprises and society. Note that in the production sphere, in many cases, the condition of fixed demand is a natural circumstance, because often in the production of certain types of industrial products, every unit counts (Kargin 2013).

Among the remaining products that do not meet the conditions (9-12), socially necessary products may also fall into the PE domain. Their characteristic curve may not correspond to the proposed conditions. The education sector mentioned above is not a physiologically conditioned service and its curve is likely to become nonzero only on the interval $L \in[2,3]$. However, the social significance of education is very high, which led to the separation of this service into a PE domain.

The production of goods in the PE domain is limited by conditions $(10,12)$. But perhaps in society there is a need for these products beyond the established limits. In this case, the excess amount would be produced in the market domain. This excess occurs in the fields of education and 
medicine where the basic need is covered free of charge, and additional services can be obtained through the market. With a political desire, it is also possible to expand the production of PE products in excess of certain norms. Then the surplus can go to the domestic or foreign market for sale.

The criteria for making a decision on production in the PE domain has been considered. These criteria answer the question "what and in what quantity is better to produce in the PE domain". Now let us consider another important question: "In what cases in society there are sufficient conditions for the transfer of some production to the PE?".

\section{Preconditions for a planned economy}

Suppose that the citizens of a country have decided to transfer a certain economic sector to a planned economy domain. The question then arises whether it is possible to somehow assess in advance the possibility of realizing this intention. Perhaps, in the economic and technical conditions existing in this country, such a reorganization would cause more negative than positive consequences.

To begin, market competition is rightly praised from different points of view. However, there are advantages and disadvantages to everything. The same market rivalry creates an uneven distribution of goods. The distribution of some product $\mathrm{P}$ in a society with competitive distribution can be graphed as:
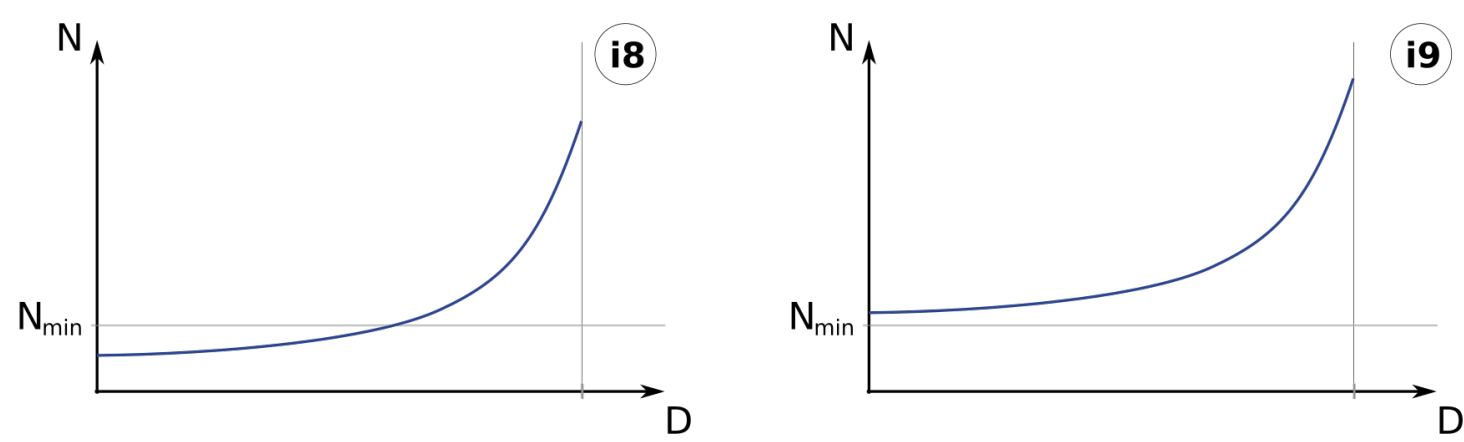

Distribution according to disposable personal wealth (D) in the market is usually biased toward the rich. Both figures show how much people consume depending on their degree of wealth. The purpose of this graph is to show the uneven distribution. In reality, there are goods (such as cheap, low-quality foods) that the rich would not buy at all. But our task is to show a qualitative picture to explain the idea. The richer have the ability to consume enough, the rest consume in the range from 
the available minimum to the sufficient amount.

If the entire population of the country would be displayed on the $\mathrm{D}$ scale so that each point represents one person, then the sum of the consumed amount of the product of all people (roughly speaking, the integral of the function N (D) over all citizens) would give the total amount of the product $\mathrm{P}$ in the period under consideration. Graph (i8) shows a situation where a significant number of people did not receive product $\mathrm{P}$ in the minimum physiologically determined amount of Nmin. On the second graph (i9), even the poorest get more than the minimum amount Nmin.

To assess the applicability of the PE, I proceed from the principle of a voluntary democratic combination of the plan and the market in the country's economy. Therefore, if the introduction of a $\mathrm{PE}$ is desired, then this should not lead to conflicts. Assume the transfer of the production of $\mathrm{P}$ to the PE domain at a production level corresponding to the first graph (i8). For an equal distribution of the minimum required product, it would be necessary to lower the consumption level of that part of the population corresponding to the line above the straight line Nmin, and transfer those products to the rest of the people, which is a conflict situation. In case (i9), such a problem does not arise, and the transfer of goods $\mathrm{P}$ in an amount corresponding to the area of the rectangle under the line Nmin to the PE domain does not lead to a redistribution of the product and would not cause a conflict.

Thus, the first prerequisite for the allocation of the PE domain was obtained: so much product $\mathrm{P}$ should be produced in society that, even after competition, everyone gets at least a physiological minimum. This premise is not a strict requirement, because theoretically it is possible to enter planned production in an amount less than Nmin, that is, in an amount corresponding to the lower point of the (i8). Conversely, this premise is desirable.

The difference between (i8) and (i9) is most likely caused by different labor productivity, that is, the total amount of goods produced at the same time by the same number of workers in case (i9) is greater. As one can see, with sufficient productivity, the transfer of production $\mathrm{P}$ to the planned domain is quite possible. However, one more condition is needed.

If some part of the citizens would be employed only in the PE domain, producing P for the entire country, then to provide these people with everything they need, productivity in the rest of the economy should be sufficient to accommodate them. A second prerequisite arises for transferring production of $\mathrm{P}$ to the PE sector: productivity outside the PE domain should be sufficient to provide 
for those employed in the PE domain.

It's all about labor productivity For this study, it would be useful to numerically estimate labor productivity and consider the dependence of the appearance of PE domains on labor productivity. However, labor productivity is not easy to measure. Various approaches to measuring labor productivity include cost, labor, natural, and index methods (Gnevasheva 2019). All methods have drawbacks and are not always directly applicable in general theoretical reasoning (Kiselkina 2015). Particular difficulties can arise when measuring the labor productivity of society as a whole. To study the planned economy, it is desirable to propose a suitable method for measuring labor productivity on the scale of the entire economy.

In general, as productivity rises, fewer people are required for productive labor. Herein, "productive labor" means the creation of material goods that ensure the life of people. As productivity rises, some people are excluded from productive work and may be engaged in other activities. For example, they can compose a state apparatus. For the emergence of state structures in which employees are occupied professionally, it was necessary to increase productivity so that the rest of society could feed this state apparatus members.

Citizens leaving the sphere of productive labor may engage in leisure or some other activity. Or they might combine work and idleness, which gradually grows into the special social phenomenon known as Bullshit Jobs (Graeber 2018). People also can go to work in the state planned economy domain. An increase in productivity is manifested in the release of citizens employed in productive labor. If productivity is considered as the percentage of those who are not employed in the productive sector of the economy, then this indicator (herein labeled "social productivity", SP) can be used for this study as a measure of labor productivity. Regarding a planned economy, it can be said that the organization of some PE domain requires an increase in social productivity by the percentage of people employed in this area. That is, for the planned domain, where $\mathrm{X}$ percent of the population is employed, it is necessary (kind of) to exclude this percent $\mathrm{X}$ from production activities, that is, to increase social productivity by this percent $\mathrm{X}$.

For example, it is possible to estimate the increase in SP for the introduction of free schooling. For Russia in 2016, 1.2 million are employed in school education (Rosstat 2021b) out of a total population of 146.5 million (Rosstat 2021a), that is, school education "cost" the country an increase in the productivity SP by $1.2 / 146.5=0.008=0.8 \%$ 
Another report (Rosstat 2021c) shows the number of medical workers in the public sector $(0.56+$ $1.3+0.27$ million). For free medicine (precisely how much medicine is actually free is irrelevant, only a rough qualitative estimate is needed) the increase in the productivity SP is $2.13 / 146.5=$ $0.014=1.4 \%$

One more domain of state subordination is partly scientific activity. The corresponding performance level of the SP for Russia is: $0.07 / 146.5=0.0005=0.05 \%$

Assuming that these values roughly show the increase in social performance required to allocate a new planned domain, one can investigate the probability of new PE domains appearing. All these values are significantly lower than the unemployment rate currently existing in many countries. (ILO Department of Statistics 2020) This suggests that today labor productivity in the world is high enough for new PE domains to appear. What can be the further development of the planned economy with an inevitable increase in social productivity? It is possible that attempts will be made to meet basic human needs, such as food, housing, heat, etc. Currently, the active topic of discussion on Unconditional Basic Income (UBI) is aimed at providing such basic needs. In contrast to a planned economy, the most widely proposed scheme for the implementation of UBI assumes the noncompetitive distribution of money, not products. However, when the topic is examined in more detail, interesting circumstances can be found that allow the question of introducing UBI in the form of a planned economy domain to be raised.

\section{Organization of a system of basic income using a planned economy. Simultaneous solution to the job guaranty problem.}

Several essential characteristics are found in many proposed schemes for the implementation of basic income, namely that UBI is distributed in cash, regularly, individually, unconditionally, and universally (Bidadanure 2019). Moreover, the provision of basic income in cash is considered as a fundamental condition. As one of the authoritative modern UBI ideologues, Philippe Van Parijs wrote, "Fundamental to the concept of a basic income is that it is paid in cash and not in the form of food, shelter, clothes, and other consumer goods" (Parijs 2017).

Parijs (2017) makes several arguments in favor of monetary basic income. These arguments are examined bearing in mind that in his consideration, Parijs does not imply the presence of planned 
and market domains side by side, but analyzes a purely market model. As I am not constrained by such a condition, I can look at the situation more broadly, examining Parijs's arguments in the case of a mixed economy.

Argument 1: "Fair and efficient distribution of cash, especially in an era of electronic payments, requires far less bureaucracy than a fair and efficient distribution of food or housing” (Parijs 2017).

In that the uniform distribution of the minimum required amount of product in the PE is considered, the problem of fair distribution does not exist. With regard to efficiency, in the case of a PE, distribution can be automated both in the sense of computer control and in the sense of automating the physical distribution of products (automatic state-owned stores serving individual cards).

Argument 2: "Cash distribution is also less prone to clientelistic pressures, lobbying of all types, and waste through misallocation" (Parijs 2017).

The argument is irrelevant in the case if a planned economy due to its insubordination to market relations. All decisions are made within the state and do not depend on private companies, the promotion of whose interests can be expressed in "lobbying." The waste of resources during distribution is difficult due to the equal distribution directly to the consumer, who knows in advance how much they will receive.

Argument 3: "when cash is distributed rather than food it creates purchasing power in the areas where poor people live, boosting local economies rather than depressing them, as the distribution of imported free food tends to do" (Parijs 2017).

Note that Parijs's reasoning in this case is not entirely logical because nothing prevents the same poor people from buying foreign products with the money received, especially if international concerns will exert price pressure on the local market. In the case of a planned economy, everything happens quite differently. First, the beauty of a PE distribution is that purchasing power is not needed to obtain free products. The task of the PE is to provide people with what they need evenly. The organization of planned production means not just stimulation, but the direct development of local production. Moreover, the work of this production is not subject to fluctuations in demand. State-owned enterprises are a strategic resource of the country, a social buffer both for providing citizens with goods and for providing citizens with jobs, which we discuss below. 
Argument 4: "Most fundamentally, a priority placed on achieving greater freedom for all carries with it a general presumption in favor of cash distribution, with no restriction as to the object or timing of its spending" (Parijs 2017).

According to the principles of organizing the PE domain outlined before, the goal is to cover the most essential needs. These needs are the same for everyone and do not allow for a wide choice of options. If a person buys bread so as not to starve, then what choice does they have? If a consumer in a planned distribution system can choose wheat or rye bread, then this is quite enough for basic income. Covering basic minimum needs does not pose a choice problem for a person, so this argument also does not work.

Thus, all arguments against providing basic income in kind are untenable in the case of a planned economy. By the way, Parijs himself notes "This presumption in favor of cash on grounds of freedom should not be embraced dogmatically, however" (Parijs 2017), and following this reasonable observation, we consider the advantages of organizing UBI in the form of a PE domain.

The graphic (i3) depicts a diagram of the distribution of products in a planned economy. Note that the logic of this diagram is similar to the UBI. Indeed, in case of PE the goods produced by the state are distributed, forming an equal basis for the life of the population. The same happens in the case of the monetary form of UBI, when money is the item produced by the state and equally distributed.

The redistribution of money occurs both in the case of a planned and in the case of a monetary method of organizing basic income. However, there is also a fundamental difference of PE compared to monetary UBI. With a planned method, money is redistributed not for the sake of increasing consumption but for the sake of creating one's own domestic production in which the citizens of the country would be employed, and the redistributed money would become their salary.

Moreover, the life base provided in kind is completely withdrawn from the monetary sphere of competition, which is a significant advantage. The point is that because money distribution is competitive, people remain in the realm of competition. The weaker ones lose in the competition. If the purpose of basic income, in particular, is to protect the weaker, then it would be much more useful to take such people out of the field of competition. The direct provision of essential needs in the case of distribution without competition provides a more reliable life base. 
Let us especially note that the introduction of an internal planned economy domain creates an opportunity for the state to attract more or fewer employees to state-owned manufacturing enterprises to guarantee the right to work. Modern monetary theory (MMT) raises the question of the need for the state to provide the opportunity to work for everyone (Mitchell 2019): "The employment buffer stock approach, which is more usually referred to in the literature as the job guarantee (JG), defines a policy framework in which the government operates a buffer stock of jobs to absorb workers who are unable to find employment in the private sector." Apparently, the creation of a planned domain of the economy can help in solving this problem, too. After all, the planned part of the economy is not limited in decision-making by the framework of market competition, which requires market profitability. In a planned economy, the concept of profit is meaningless. Nothing prevents providing those in need and willing to work such job where their skills will be useful. Since the PE does not require profitability, it is possible to invest much more labor (which would otherwise not be in demand) in the final product compared to a market economy. This way, high quality can be achieved. In any case, this approach will bring more benefits than social payments to the same people without any contribution to public welfare on their part.

\section{Conclusion}

Based on the critical analysis of the planned economy seen in the classic texts, some important characteristics of PE were identified. The following quality was added to the usually indicated list of properties of a planned economy: the PE area produces a limited amount of necessary goods of irreducible demand, then these goods are distributed among all members of society free of charge, evenly, without competition. Considering these additions, it appears that the planned approach naturally combines with the market approach, which allows for the creation of a more harmonious and sustainable economic system. Each of the two, the planned and market methods of organizing the economy, can be applied where it brings the greatest benefits to society. Recommendations were provided for determining where to best apply the model in a planned economy. Conclusions showed that the planning approach is well suited for organizing a system of unconditional basic income. In addition, the planned economy has proved to be a useful tool for solving the problem of guaranteed employment.

\section{References}


Berg, A.I., Kitov, A.I., \& Lyapunov, A.A. (1959). On the possibilities of automating the management of the national economy. Problems of Cybernetics: Collection of Articles., No. $6,83-100$.

Bidadanure, J.U. (2019). The Political Theory of Universal Basic Income. Annual Review of Political Science. 22 , 481-501

Buletova [et al.] (2014). Statistical methods of research of macroeconomic phenomena and processes / N. Ye.; Publishing house of the Volgograd Phil. Fgbou vpo ranepa

EMISS. (2021). Consumption of basic foodstuffs (per capita). Unified Interdepartmental Statistical Information System (EMISS). https://fedstat.ru/indicator/31346

Graeber, D. (2018). Bullshit Jobs. A Theory. The Anarchist Library, Anti-Copyright

Glushkov V.M. (1975). Macroeconomic models and principles of OGAS construction. M., "Statistics".

Gnevasheva, V.A. (2019). Estimates of labor productivity in Russia. Regional problems of economic transformation, (3 (101)), 107-113.

Hayek, F.A. (2005). The road to serfdom. New publishing house. (Original work published 1944)

Jevons, W. Stanley. (1871). The theory of political economy. London: Macmillan and. Co.

ILO Department of Statistics. (2020). Unemployment and labour underutilization. ILOSTAT.

Retrieved June 23, 2021, from https://ilostat.ilo.org/topics/unemployment-and-labourunderutilization/

Kargin, E.S. (2013). A new look at the public sector of the economy. Economic revival of Russia, (3 (37)) , 114-124. (ru)

Kantor, Lazar (1964) Price formation in the USSR Publishing house "Economy" (ru)

Kiselkina, O.V. (2015). Problems of measuring labor productivity. Bulletin of Economics, Law and Sociology. No. 4, 43-46. (ru)

Kornai, Janos (1990) Shortage. Publishing house "Science" Moscow (ru)

Lavoie, Don (1985) Rivalry and central planning. The socialist calculation debate reconsidered. Cambridge university press

Mises, L. (1990). Economic Calculation in the Socialist Commonwealth. Ludwig von Mises Institute. (Original work published 1920)

Mises, L. (1998). Human action. A Treatise on Economics. The Scholars Edition Ludwig von Mises Institute. (Original work published 1949)

Mises, L. (1962). Socialism. An Economic and Sociological Analysis. New haven Yale university press 
Mitchell W., Wray R., \& Watts, M. (2019) Macroeconomics. Red Globe Press

Parijs P.V. \& Yannick V. (2017) Basic Income. A Radical Proposal for a Free Society and a Sane Economy. Harvard University Press

Presidium of the Supreme Council of the RSFSR (1963) Decree of May 6, 1963. On strengthening responsibility for feeding livestock and poultry bread and other bakery products purchased in state and cooperative stores. http://www.libussr.ru/doc_ussr/usr_5948.htm

Rosstat (2021a). The size and composition of the population. Federal State Statistics Service. https://rosstat.gov.ru/folder/12781 (ru)

Rosstat. (2021b). Results of federal statistical observation in the field of remuneration of certain categories of workers in the social sphere and science for January-March 2019.

Federal State Statistics Service. https://rosstat.gov.ru/storage/mediabank/itog-monitor0119(1).html (ru)

Rosstat. (2021c). The number of certain categories of workers in the social sphere and science. Federal State Statistics Service. http://www.gks.ru/storage/mediabank/01-19-13.xlsx (ru) Rizhiy Pavel, Pass Andrei (2012) Nationalization of industrial co-operation in the soviet union in the second half of the 1950s: causes and consequences. Society and power. No. 5(37) (ru) Stalin I. (1952) Economic problems of socialism in the USSR. Gospolitizdat (ru) 